Research Article

\title{
High-Temperature Rutting Resistance of Inverted Asphalt Pavement Structure
}

\author{
Yingjun Jiang $(\mathbb{D}$, Yu Zhang $(\mathbb{D}$, Changqing Deng $(\mathbb{D}$, Yong Yi $\mathbb{( D}$, Tian Tian $(\mathbb{D}$, \\ and Kejia Yuan $(\mathbb{D}$
}

Key Laboratory for Special Area Highway Engineering of Ministry of Education, Chang'an University, Xi'an,
Shaanxi 710064, China

Correspondence should be addressed to Changqing Deng; changqingdeng@chd.edu.cn

Received 16 November 2019; Revised 21 July 2020; Accepted 23 July 2020; Published 12 August 2020

Academic Editor: Valeria Vignali

Copyright (C) 2020 Yingjun Jiang et al. This is an open access article distributed under the Creative Commons Attribution License, which permits unrestricted use, distribution, and reproduction in any medium, provided the original work is properly cited.

To improve the high-temperature rutting resistance of asphalt pavements, an inverted asphalt pavement structure (IAPS), $4 \mathrm{~cm}$ AC-13 mixture $+8 \mathrm{~cm}$ AC-25 mixture $+6 \mathrm{~cm}$ AC-20 mixture $+54 \mathrm{~cm}$ cement-stabilized macadam, was proposed herein by considering engineering practice, theoretical calculation, and analysis. A rutting prediction equation of asphalt pavements was then proposed via rut-development trends found by laboratory $18 \mathrm{~cm}$ thick rutting test. Subsequently, the rutting resistance of the IAPS was evaluated. The results show that, compared with the traditional asphalt pavement structure (TAPS), $4 \mathrm{~cm}$ AC-13 mixture $+6 \mathrm{~cm}$ AC-20 mixture $+8 \mathrm{~cm}$ AC- 25 mixture $+54 \mathrm{~cm}$ cement-stabilized macadam, the maximum shear stress of the IAPS can be reduced by $\sim 1.7 \%$ along with improvements in rutting resistance by $\sim 16 \%$ and $\sim 12 \%$ under wheel loads of 0.7 and $1.2 \mathrm{MPa}$, respectively. Wheel-load increase affects the rutting resistance of both structures in a similar manner: when the wheel load increases from 0.7 MPa to 1.2 MPa, the rut depths of both pavement structures increase by at least $63 \%$. The IAPS clearly has better rutting resistance than the TAPS and is thus the better choice for asphalt pavement structure design.

\section{Introduction}

Asphalt pavements offer advantages such as a flat surface, comfortable driving, low noise, fast construction, and simple maintenance and repairs. Therefore, they are widely used for paving roads all over the world [1,2]. However, as global temperatures continue to rise and as heavy-duty and channelized traffic become increasingly commonplace, the usage conditions of asphalt pavements have become increasingly demanding, resulting in the reduced service life of typical asphalt pavements. Nowadays, insufficient durability has become the primary problem associated with the usage of asphalt pavements [3], often caused by pavement rutting [4,5].

Road engineers throughout the world have investigated various strategies for improving the asphalt pavement's resistance to rutting at high temperatures [5-27]. Additives such as styrene-butalene-styrene (SBS) [6], ethylene copolymer [7], epoxy resin [8], rock asphalt [9], nanoparticles [10], highmodulus modifier [11], crumb rubber [12], and anti-rutting additives [13] have been used to enhance the rheological properties of asphalt binders and to improve the rutting resistance of the asphalt mixtures. Kim et al. [14] and Bernier et al. [15] studied the effect of the amount of recycled asphalt pavement materials on the anti-rutting performance of polymer-modified asphalt. They observed that the incorporation of recycled asphalt pavement materials can improve the rutting resistance of the asphalt mixtures. Hydrated lime [16, 17], graphite [18], and steel slag $[19,20]$ have been mixed into the asphalt mixtures to partially replace the mineral filler or the asphalt mixture. Subsequently, the high-temperature performances of the corresponding modified mixtures were evaluated. The results indicated that such mixtures exhibit better rutting resistance than the control asphalt mixture. Coleri et al. observed that dense gradation and large aggregate size improve aggregate interlocking, which can effectively disperse the shear stress distribution within the asphalt pavement, improving the shear resistance and the high-temperature performance [21]. Shanbara et al. found that, compared with the conventional 
cold and hot mixtures, the cold mix asphalt reinforced with the natural and synthetic fibers shows better resisting permanent deformation damage $[22,23]$. Reflective cool pavements can prevent the occurrence of urban heat islands as well as the occurrence of pavement rutting to a certain extent [24-27]. The aforementioned studies have undoubtedly helped improve the high-temperature rutting resistance of asphalt pavements by improving the high-temperature performance of the asphalt binder and asphalt mixtures or reducing the pavement temperature. However, they have rarely considered performing improvements by optimizing the asphalt pavement structure combination.

In China, the upper, middle, and lower layers of asphalt pavements have conventionally used aggregates in the order of fine, medium, and coarse, or in the order of fine, medium, and medium granular in asphalt mixtures. Furthermore, the asphalt mixture of each structural layer is designed to exhibit the complete range of functional requirements; i.e., each asphalt structural layer is designed to achieve good rutting resistance, cracking resistance, and moisture sensitivity. Researchers have observed that pavement rutting mainly appears in the middle layer of the asphalt pavement structure; therefore, the middle-layer mixtures must be designed to be the most resistant to rutting [28-30]. However, low-temperature crack resistance and moisture sensitivity of the middle-layer mixtures are also considered during the asphalt mixture design; thus, maximizing the rutting resistance of the middle layer is impossible. Moreover, a previous study has proved that the lower-layer mixtures mainly provide resistance to fatigue cracking in asphalt pavements; therefore, the lower-layer mixtures should exhibit good crack resistance. However, these mixtures are typically designed to provide temperature stability and moisture sensitivity; therefore, the crack resistance of these mixtures is not maximized [31]. Therefore, it is significantly important to design the asphalt pavement structure according to the individual functional needs of each asphalt structural layer.

This study thereby intends to improve the typical semirigid base asphalt pavement structure with an inverted asphalt pavement structure (IAPS), wherein the middle and lower layers of the standard asphalt pavement are switched. Subsequently, the BISAR 3.0 software and a custom-built rut-testing rig were used to test the resistance of $18 \mathrm{~cm}$ thick slab specimen. The test results offer significant improvements in the asphalt pavement structure design.

\section{Inverted Asphalt Pavement Structure and Theoretical Verification}

2.1. Inverted Asphalt Pavement Structure. Structural engineers have observed that, in three-layered asphalt pavements, ruts typically originate in the middle layer [28-30]. Theoretical studies have also denoted that the maximum shear stress of the semi-rigid base asphalt pavement gradually shifts downward with an increase in load pressure; however, this stress is always observed in the middle layer $[32,33]$. Therefore, the middle layer of asphalt pavements should have sufficient high-temperature rutting resistance $[32,33]$. The nominal maximum particle size of the aggregate significantly affects the high-temperature stability of an asphalt mixture. Large nominal particle sizes have been observed to improve the high-temperature rutting resistance of the asphalt mixture [34]. This observation inspired the IAPS, in which the bottom two layers of the pavement structure typically applied in China were switched. The properties of all the layers in both pavement structure types are presented in Table 1, where TAPS represents the traditional asphalt pavement structure.

\subsection{Theoretical Verification of the Inverted Asphalt Pavement Structure}

2.2.1. Calculation Parameter. Table 2 shows the parameter that is used for calculating the stress in different asphalt pavement structures. The moduli of the AC-13, AC-20, and AC-25 asphalt mixtures were tested in the laboratory according to the Standard Test Methods of Bitumen and Bituminous Mixtures for Highway Engineering (JTG E202011) [35], and the test temperature was set to $20^{\circ} \mathrm{C}$. The Poisson's ratios of the monolithic materials, including the asphalt mixtures and the cement-stabilized macadam base, and the bulk material (soil base) were observed to be 0.25 and 0.4 , respectively.

2.2.2. Calculation Results. The stress distributions in the two asphalt pavement structures were calculated using the BISAR 3.0 software. The calculation results of the maximum shear stress in the two asphalt pavement structures are presented in Table 3 , where $\sigma_{\text {TAPS }}$ and $\sigma_{\text {IAPS }}$ denote the maximum shear stress of the TAPS and IAPS, respectively. It is noteworthy that an asphalt pavement structure is considered to be a linear elastic layer system in these stress calculations, and the interlayer contact is modeled to be completely continuous.

Table 3 shows that the maximum shear stress of the IAPS is lower than that of the TAPS by $1.7 \%$. This indicates that the IAPS can improve the high-temperature rutting resistance of the asphalt pavement.

\section{Rutting Test Verification of the Inverted Asphalt Pavement Structure}

\subsection{Raw Materials and Mixtures}

3.1.1. Asphalt Binder. The SBS (I-C)-modified asphalt, produced by Zhejiang Yinji Petrochemical Co. Ltd. (Zhejiang Province, China), was used as the binder for the AC-13 asphalt mixture and as the gluing material between two asphalt layers. Class A-70\# matrix asphalt, produced by the Zhenhai Refining \& Chemical Company (Zhejiang Province, China), was used as the binder for the AC-20 and AC-25 asphalt mixtures. The technical properties of the two asphalt binders are presented in Table 4.

3.1.2. Aggregate. Crushed basalt was used as the coarse aggregate for the AC-13 asphalt mixture, whereas crushed limestone was used as the coarse aggregate for the AC-20 
TABLE 1: Layer structure of the TAPS and IAPS.

\begin{tabular}{|c|c|c|}
\hline Pavement structures & TAPS & IAPS \\
\hline Upper layer & $4 \mathrm{~cm} \mathrm{AC-13} \mathrm{mixture}$ & $4 \mathrm{~cm} \mathrm{AC-13} \mathrm{mixture}$ \\
\hline Middle layer & $6 \mathrm{~cm} \mathrm{AC-20} \mathrm{mixture}$ & $8 \mathrm{~cm} \mathrm{AC-25} \mathrm{mixture}$ \\
\hline Lower layer & $8 \mathrm{~cm} \mathrm{AC}-25$ mixture & $6 \mathrm{~cm} \mathrm{AC-20} \mathrm{mixture}$ \\
\hline Base & $54 \mathrm{~cm}$ cement-stabilized macadam & $54 \mathrm{~cm}$ cement-stabilized macadam \\
\hline Soil base & - & - \\
\hline
\end{tabular}

TABLE 2: Calculation parameter of the materials.

\begin{tabular}{lccccc}
\hline Calculation parameter & \multicolumn{3}{c}{ Types of material } \\
& AC-13 & AC-20 & AC-25 & Base & Soil base \\
\hline Modulus $(\mathrm{MPa})$ & 897 & 985 & 1141 & 1500 & 50 \\
\hline
\end{tabular}

TABLE 3: The calculated maximum shear stress of the two asphalt pavement structures.

\begin{tabular}{lccc}
\hline Location & \multicolumn{3}{c}{ Maximum shear stress for the following pavement structures $(\mathrm{MPa})$} \\
& TAPS & IAPS & $\left(\sigma_{\text {IAPS }} / \sigma_{\text {TAPS }}\right)(\%)$ \\
\hline Asphalt layers & 0.230 & 0.226 & 98.3 \\
\hline
\end{tabular}

TABLE 4: Technical properties of the asphalt binders.

\begin{tabular}{lccccc}
\hline Asphalt binders & $\begin{array}{c}\text { Penetration }\left(25^{\circ} \mathrm{C}, 100 \mathrm{~g}, 5 \mathrm{~s}\right) \\
(0.1 \mathrm{~mm})\end{array}$ & $\begin{array}{c}\text { Ductility } \\
(\mathrm{cm})\end{array}$ & $\begin{array}{c}\text { Softening point } \\
\left({ }^{\circ} \mathrm{C}\right)\end{array}$ & $\begin{array}{c}\text { Flash point } \\
\left({ }^{\circ} \mathrm{C}\right)\end{array}$ & \begin{tabular}{c} 
Density $\left(15^{\circ} \mathrm{C}\right)\left(\mathrm{g} / \mathrm{cm}^{3}\right)$ \\
\hline SBS-modified
\end{tabular} \\
$\begin{array}{l}\text { asphalt } \\
70 \# \text { matrix asphalt }\end{array}$ & 67 & $36.4\left(5^{\circ} \mathrm{C}\right)$ & 72.5 & 320 & 1.035 \\
\hline
\end{tabular}

and AC-25 asphalt mixtures. The fine aggregate and mineral powder that were used for the AC-13 and those for AC-20 and AC-25 asphalt mixtures were crushed limestone and limestone ore, respectively. The coarse aggregate, fine aggregate, and mineral powder were produced by the Jinhua Pan'an Stone Material Factory (Zhejiang Province, China), and each material satisfied the requirements mandated by the Technical Specification for Construction of Highway Asphalt Pavements (JTG F40-2004) [36].

3.1.3. Gradation. The aggregate gradations of the asphalt mixtures that are used in this study are presented in Table 5.

3.1.4. Mix Design. In this study, the AC-13, AC-20, and AC25 asphalt mixtures were designed using the Marshall design procedure. The mixture design and road performance test results of the AC-13, AC-20, and AC-25 asphalt mixtures are presented in Tables 6 and 7, respectively, where VV, VMA, VFA, DS, $\varepsilon_{B}, \mathrm{MS}_{0}$, and TSR denote the air void volume, voids in mineral aggregate, volume of voids filled with asphalt, dynamic stability, flexural tensile strain, retained Marshall stability, and freeze-thaw splitting strength ratio, respectively. VV, VMA, VFA, DS, $\varepsilon_{B}, \mathrm{MS}_{0}$, and TSR were verified according to the Standard Test Methods of Bitumen and Bituminous Mixtures for Highway Engineering (JTG E20-2011) [35].

The results in Table 7 denote that the road performance indicators, such as DS, $\varepsilon_{B}, \mathrm{MS}_{0}$, and TSR, of the asphalt mixtures used in this study satisfy the technical requirements of the Technical Specification for Construction of Highway Asphalt Pavements (JTG F40-2004) [36]. The dynamic stability of the AC-25 asphalt mixture is notably higher than that of the AC-20 asphalt mixture.

\subsection{Test Method}

3.2.1. Preparation of the $18 \mathrm{~cm}$ Thick Slab Specimen. Considering that the traditional slab specimen forming instrument can produce slab specimens with a thickness of $3-10 \mathrm{~cm}$, the $18 \mathrm{~cm}$ thick slab specimen was prepared using a custom-built slab specimen forming instrument. The main technical indexes and parameters of the custom-built instrument are identical to those of the traditional instrument; however, the custom-built instrument can produce slab specimens with a thickness of 3-20 cm.

To simulate the actual field conditions of the upper, middle, and lower asphalt layers, the slab specimen was prepared in the laboratory as follows:

(1) The lower-layer slab specimen: first, a $300 \mathrm{~mm} \times 300 \mathrm{~mm}$ layer of board (see Figure 1) was produced using the custom-built slab specimen forming instrument, satisfying the layer-wise thickness requirement denoted in Table 1 . When the lower layer was AC-20 asphalt mixture, the thickness of the produced slab specimen was $6 \mathrm{~cm}$; when AC25 asphalt mixture was used as the lower layer, the 
TABle 5: Aggregate gradations of different asphalt mixtures.

\begin{tabular}{lccccccccccccc}
\hline \multirow{2}{*}{ Gradations } & \multicolumn{10}{c}{} & \multicolumn{10}{c}{ Passing rate (\%) of the following sieve size (mm) } \\
& 31.5 & 26.5 & 19 & 16 & 13.2 & 9.5 & 4.75 & 2.36 & 1.18 & 0.6 & 0.3 & 0.15 & 0.075 \\
\hline AC-13 & 100 & 100 & 100 & 100 & 91.7 & 76.9 & 46.5 & 33.9 & 22.3 & 16.4 & 11.9 & 10.0 & 6.8 \\
AC-20 & 100 & 100 & 89.9 & 78.8 & 60.2 & 45.6 & 33.4 & 25.7 & 18.3 & 13.7 & 10.7 & 7.6 & 6.4 \\
AC-25 & 100 & 95.0 & 80.3 & 70.7 & 62.3 & 51.2 & 38.1 & 24.6 & 17.2 & 10.6 & 7.4 & 6.0 & 5.0 \\
\hline
\end{tabular}

TABLE 6: Marshall design results for different asphalt mixtures.

\begin{tabular}{lccccc}
\hline Mixture types & Optimum asphalt content $(\%)$ & Density $\left(\mathrm{g} / \mathrm{cm}^{3}\right)$ & VV $(\%)$ & VFA $(\%)$ & VMA $(\%)$ \\
\hline AC-13 & 5.8 & 2.496 & 4.3 & 70.9 & 17.4 \\
AC-20 & 4.4 & 2.437 & 4.2 & 69.3 & 14.1 \\
AC-25 & 3.8 & 2.447 & 5.0 & 66.9 \\
\hline
\end{tabular}

TABle 7: Performance test results of different asphalt mixtures.

\begin{tabular}{lcccc}
\hline $\begin{array}{l}\text { Mixture } \\
\text { types }\end{array}$ & $\begin{array}{c}\mathrm{DS} \\
(\mathrm{times} / \mathrm{mm})\end{array}$ & $\varepsilon_{B}\left(\mu \varepsilon \times 10^{-6}\right)$ & $\begin{array}{c}\mathrm{MS}_{0} \\
(\%)\end{array}$ & $\begin{array}{c}\text { TSR } \\
(\%)\end{array}$ \\
\hline AC-13 & 5337 & 3226 & 92.1 & 82.2 \\
AC-20 & 2041 & 2577 & 88.9 & 81.9 \\
AC-25 & 2697 & 2439 & 86.1 & 78.5 \\
\hline
\end{tabular}

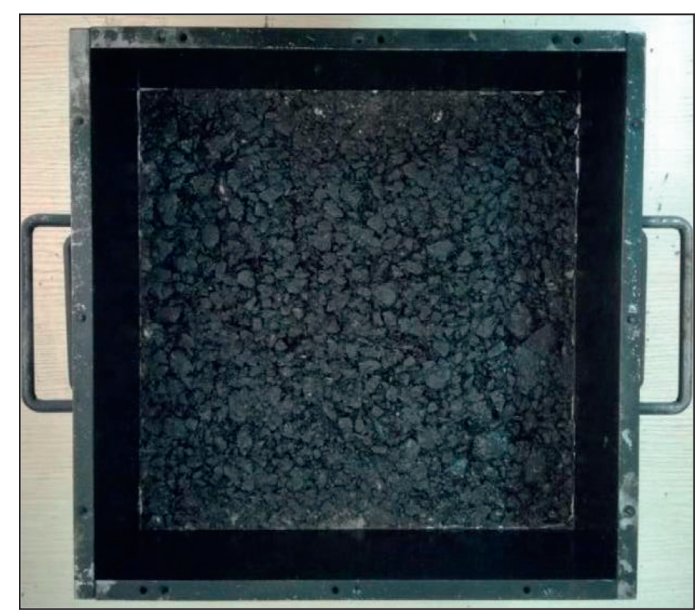

Figure 1: The prepared lower-layer specimen.

board thickness was $8 \mathrm{~cm}$. Then, the slab specimens were placed at room temperature for at least $24 \mathrm{~h}$. Subsequently, the SBS-modified asphalt weighing $0.4 \mathrm{~L} / \mathrm{m}^{2}$ was evenly sprayed on the slab specimen surface and was cured for at least $2 \mathrm{~h}$.

(2) The middle-layer slab specimen: the middle-layer slab specimen was produced and applied on the lower-layer slab specimen sprayed with the sticky layer oil, with thicknesses as specified in Table 1. When the AC-20 asphalt mixture was used as the middle layer, the board thickness was $6 \mathrm{~cm}$; when the AC-25 asphalt mixture was used as the middle layer, its thickness was $8 \mathrm{~cm}$. The SBS-modified asphalt weighing $0.4 \mathrm{~L} / \mathrm{m}^{2}$ was evenly sprayed on the surface of the prepared middle-layer slab specimen, which was subsequently cooled at room temperature for 24 h.
(3) The upper-layer slab specimen: finally, the $4 \mathrm{~cm}$ thick top-layer slab specimen was produced and applied on the middle-layer slab specimen sprayed with the sticky layer oil. Subsequently, it was cooled at room temperature for $48 \mathrm{~h}$. The production process of the upper-layer slab specimen is depicted in Figure 2.

Each asphalt layer was produced with the optimal asphalt content and the mixture density specified in the Standard Test Methods of Bitumen and Bituminous Mixtures for Highway Engineering (JTG E20-2011) [35]. To ensure the reliability of the rutting tests, the porosity difference in all slab specimens was maintained within $1 \%$ from that of the respective standard cylindrical specimens [37]. The demolded $18 \mathrm{~cm}$ thick slab specimen is denoted in Figure 3 .

3.2.2. Rutting Test. The rutting test was conducted on a custom-made rutting tester for a thick slab specimen $(18 \mathrm{~cm}$ thick). The main difference between the traditional rutting tester and the custom-made rutting tester is that the former can be used only to test the rutting depth of the slab specimen with a height of $5-10 \mathrm{~cm}$, whereas the custommade rutting tester can be used to measure the rutting depth of the slab specimen with a height of $5-20 \mathrm{~cm}$. Other test procedures of the custom-made and traditional rutting tester are identical. For the rutting test, the test temperature was $60^{\circ} \mathrm{C}$, the loading rate was 42 times/min, the total testing time was $10 \mathrm{~h}$, and the wheel loads were 0.7 and $1.2 \mathrm{MPa}$.

The Standard Test Methods of Bitumen and Bituminous Mixtures for Highway Engineering (JTG E20-2011) [35] specifies that the prepared slab specimen should be placed into a constant-temperature $\left(60^{\circ} \mathrm{C}\right)$ oven before testing to ensure that the internal temperature of the slab specimen is equal to the temperature at which rutting occurs. Generally, when the slab specimen is $5-10 \mathrm{~cm}$ thick, the holding time of the slab specimen in a $60^{\circ} \mathrm{C}$ oven should be $5-12 \mathrm{~h}$. However, the slab specimen investigated in this study is thicker than most other samples (at $18 \mathrm{~cm}$ ), and we could find no reference data to indicate the duration for which thick slab specimens should be kept in the oven. If the holding time is too short, the internal temperature of the slab specimen will not reach the mandated test temperature; however, if the 


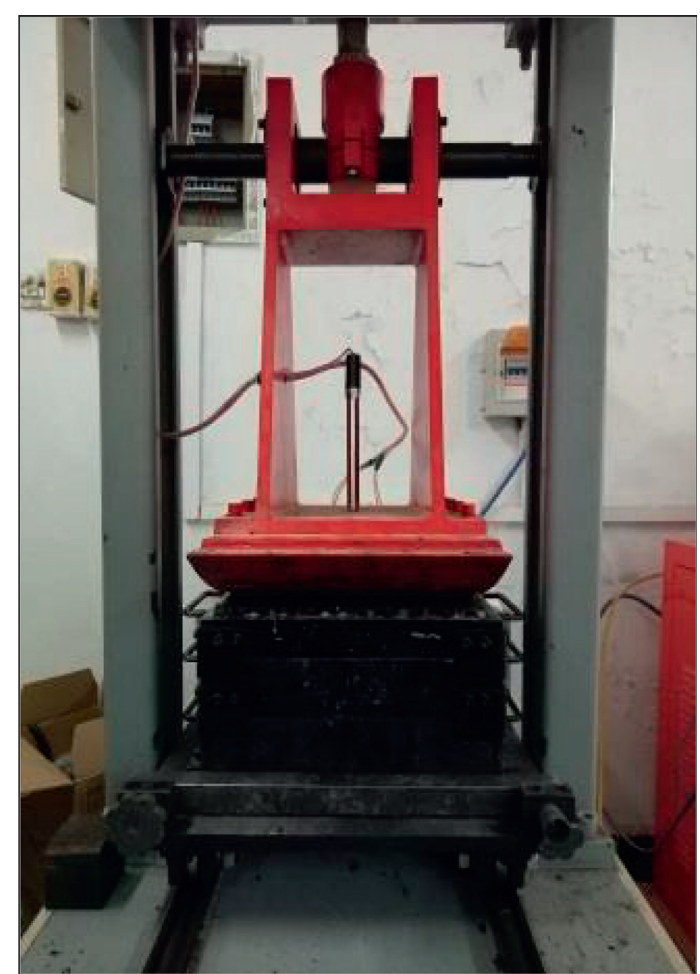

Figure 2: Production of upper-layer specimen.

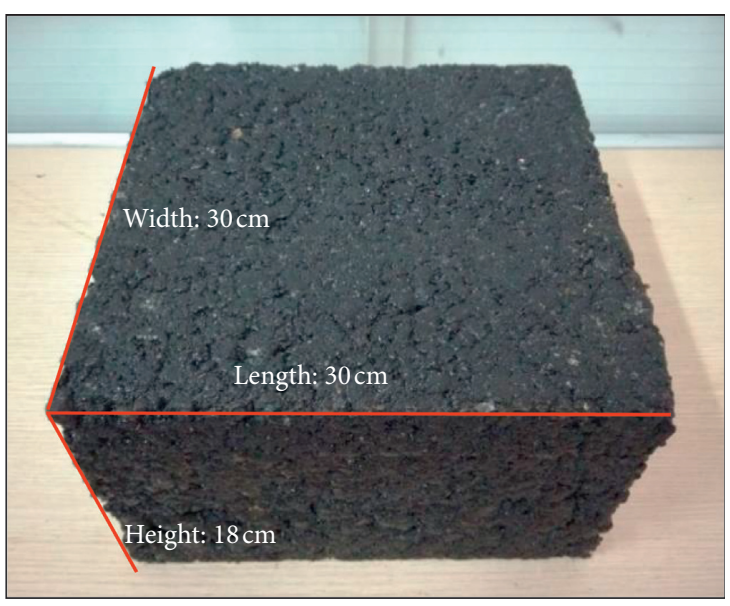

FIgURE 3: The prepared $18 \mathrm{~cm}$ thick specimen.

holding time is too long, the binder and mixtures will age, affecting the reliability of the test results. Therefore, the relationship between the holding time and the internal temperature of the $18 \mathrm{~cm}$ thick slab specimen was recorded in preliminary tests and is depicted in Figure 4. During the test, the temperature of the oven was maintained to be constant at $60^{\circ} \mathrm{C}$. The internal temperatures between the upper and middle asphalt layers and those between the middle and lower asphalt layers were tested using temperature sensors that were embedded within the pavement layers during the slab specimen preparation. The temperature test procedure is shown in Figure 5.

As shown in Figure 4, when the holding time of a slab specimen is lower than $4 \mathrm{~h}$, the internal temperatures of the

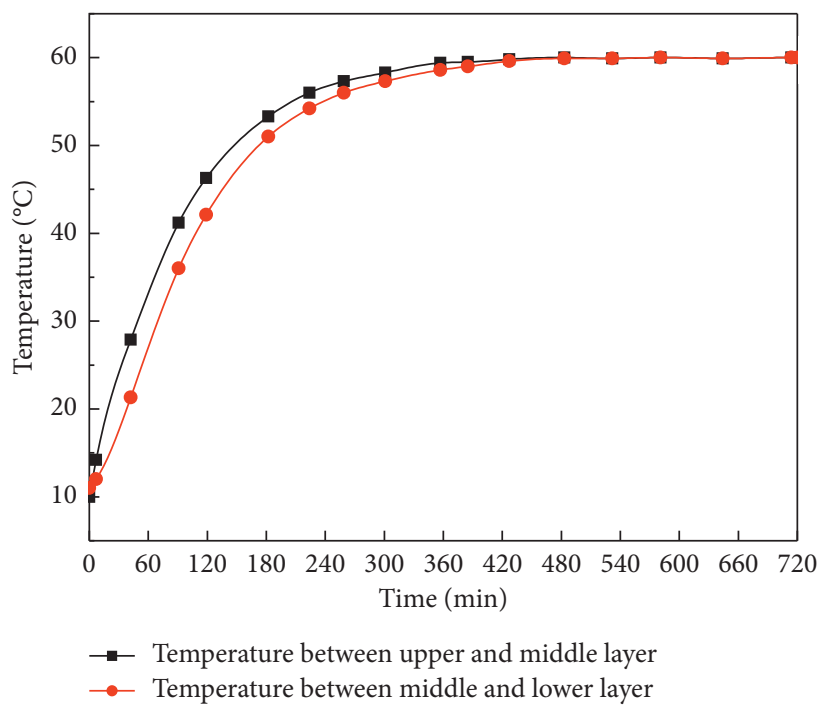

Figure 4: Relationship between the internal temperature and holding time of the slab specimen.

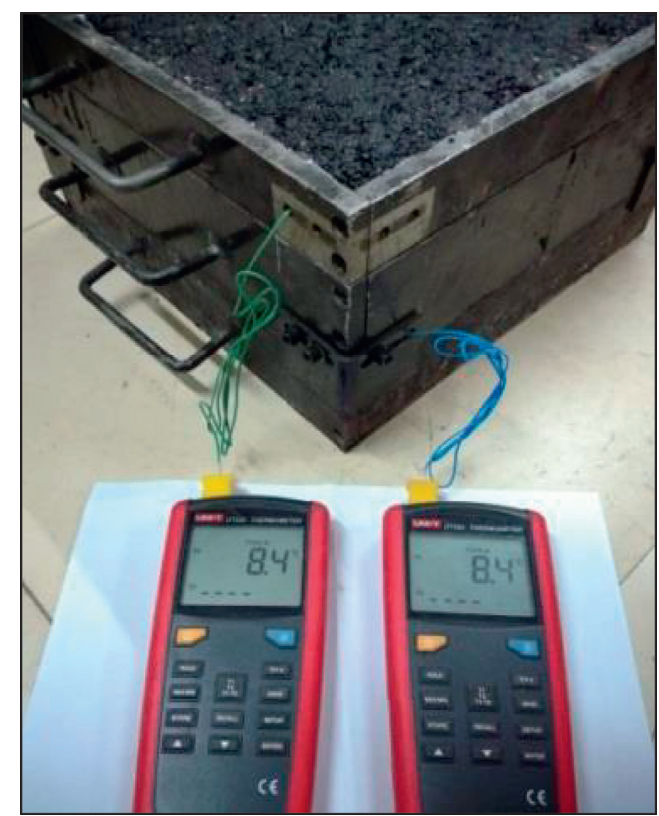

FIGURE 5: Internal temperature test of $18 \mathrm{~cm}$ thick slab specimen.

$18 \mathrm{~cm}$ thick slab specimen increase sharply with increase in the holding time. When the holding time is $4 \mathrm{~h}$, the internal temperatures of the slab specimen reach $55^{\circ} \mathrm{C}$; furthermore, when the holding time is $8 \mathrm{~h}$, the internal temperatures of the slab specimen are stable at $\sim 60^{\circ} \mathrm{C}$, which is the temperature at which the loading tests are conducted. Therefore, to ensure that the internal temperatures of the slab specimen are equal to the mandated rutting test temperature, we suggest that the holding time of an $18 \mathrm{~cm}$ thick slab specimen should be kept in an oven at $60^{\circ} \mathrm{C}$ for $8 \mathrm{~h}$.

\section{Results and Discussion}

4.1. Rutting Test Results. Figure 6 shows the laboratory rutting test process of the $18 \mathrm{~cm}$ thick slab specimen. 


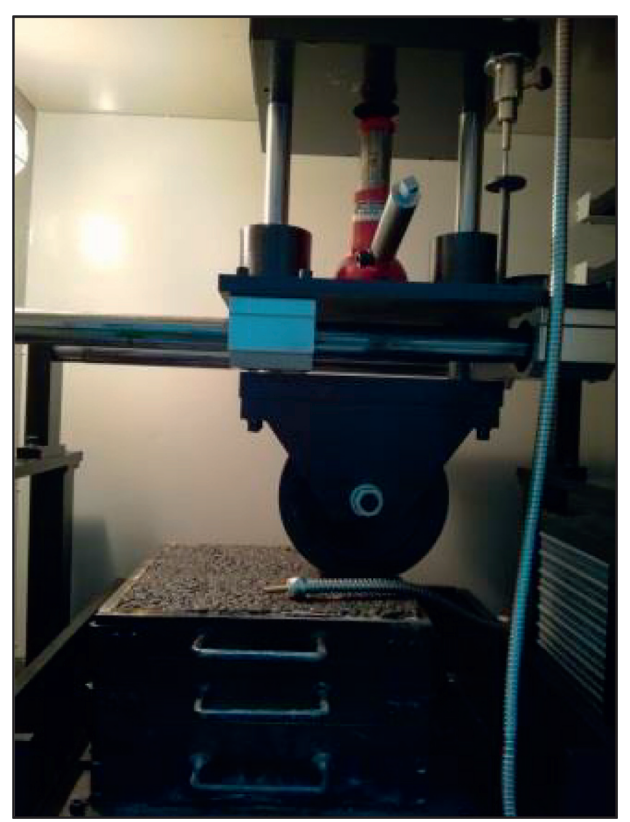

FIGURE 6: Rutting test process.

Moreover, the rutting test results of slab specimens in different pavement structures are presented in Table 8 .

As denoted by the results in Table 8 , the cumulative rut depths of the two asphalt pavement structures under different wheel loads increase as the number of load cycles increases. Furthermore, the cumulative rut depths of the IAPS samples tend to be smaller than those of the TAPS when the load cycles and wheel loads are the same. Considering that the number of the testing samples is small, an analysis of variance test was conducted to examine the differences between the rut depths of two pavement structures $[38,39]$. Tables 9 and 10 present the significant test results of the two pavement structures under wheel loads of $0.7 \mathrm{MPa}$ and 1.2 $\mathrm{MPa}$, respectively.

As presented in Tables 9 and 10, the differences between the rut depths of the TAPS and IAPS samples that are subjected to the same number of load cycles are significant. These findings show that the IAPS sample is more resistant against rutting than the TAPS sample.

\subsection{Rut-Development Trend and Prediction Equation}

4.2.1. Development of Rut. According to the results presented in Table 8 , the development trend of the cumulative rut depth of different pavement structures is plotted against the number of the loading cycles in Figure 7.

It can be seen from Figure 7 that the shapes of the rutdevelopment curves of both pavement structures are very similar when plotted against the increase of the number of loading cycles. When the number of loading cycles is less than 2550, the cumulative rut depths of both pavement structures increase sharply as the number of load cycles increases. However, after 2550 load cycles, the rate of increase in the cumulative rut depths of both structures decreases gradually until the rut depth stabilizes. The permanent deformation of asphalt mixture is mainly classified into three stages. During the first stage, the cumulative rut depths increase sharply as the number of load cycles increases. During the second stage, the rate of increase of the cumulative rut depths decreases gradually and eventually stabilizes. In the third stage, the strain rate grows rapidly with the increases of loading cycles. The material structure loses its stability under shear and finally results in the failure of the material [40]. Thus, Figure 7 only shows the first and second stage of the permanent deformation of asphalt mixture during the rutting experiment.

4.2.2. Rutting Prediction Equation. The rut-development stages of asphalt pavement structures, as shown in Figure 7, indicate that there exists a horizontal asymptotic line during the second stage of permanent deformation of slab specimen in the rut-development curve. Furthermore, the corresponding value of the asymptote during the second stage of permanent deformation can be interpreted as the maximum rut depth $\left(\mathrm{RD}_{\max }\right)$. We assume that the development of ruts during the first and second stages in asphalt pavement structures follows a rutting prediction equation, which should satisfy the following two boundary conditions:

$$
\begin{aligned}
& \text { when } N=0, \operatorname{RD}(0)=\mathrm{RD}_{0}=0 \text { and } \\
& \text { when } N=\infty, \operatorname{RD}(\infty)=\mathrm{RD}_{\text {max }} \text {, }
\end{aligned}
$$

Where $N$ denotes the number of loading cycles, $\mathrm{RD}(0)$ denotes the rut depth $(\mathrm{mm})$ of the slab specimen before any loading has been applied, and $\mathrm{RD}(\infty)$ denotes the rut depth $(\mathrm{mm})$ of the slab specimen at the number of final loading cycles of the second stage.

Furthermore, we fitted the resulting curves to establish the following equation according to the aforementioned boundary conditions:

$$
\mathrm{RD}(N)=\frac{\mathrm{RD}_{\max } \times N}{N+\xi},
$$

where $\mathrm{RD}(N)$ denotes the rut depth $(\mathrm{mm})$ of slab specimen after $N$ loading cycles and $\mathrm{RD}_{\max }$ and $\xi$ are the regression coefficients.

Equation (1) was used to fit the data presented in Table 8, and the resulting values of the coefficients $\mathrm{RD}_{\max }, \xi$, and $R^{2}$ are presented in Table 11.

Table 11 shows that the correlation coefficients $R^{2}$ of the rutting prediction equation are greater than 0.98 , indicating that the rutting prediction equation proposed in this study can accurately predict the development trend of rutting in the asphalt pavement structures.

\subsection{Factors Influencing the Rutting Test}

4.3.1. Effect of Wheel Load on Pavement Rutting. According to the values presented in Table 11, the effect of the wheel load on the maximum rut depth of the asphalt pavement structure is denoted in Table 12, where $\left(\mathrm{RD}_{1.2} / \mathrm{RD}_{0.7}\right)$ denotes the ratio of the maximum rut depth of the slab specimen under the wheel load of $1.2 \mathrm{MPa}$ to that under the wheel load of $0.7 \mathrm{MPa}$. 
TABLE 8: Rutting test results of the slab specimens in different pavement structures.

\begin{tabular}{|c|c|c|c|c|c|c|c|c|c|c|c|c|c|}
\hline \multirow{2}{*}{ Load (MPa) } & \multirow{2}{*}{ Pavement structures } & \multirow{2}{*}{ Samples no. } & \multicolumn{11}{|c|}{ Cumulative rut depths $(\mathrm{mm})$ of the following load cycles (times) } \\
\hline & & & 0 & 2550 & 5100 & 7650 & 10200 & 12750 & 15300 & 17850 & 20400 & 22950 & 25500 \\
\hline \multirow{6}{*}{0.7} & \multirow{3}{*}{ TAPS } & 1 & 0 & 1.772 & 2.109 & 2.291 & 2.45 & 2.572 & 2.646 & 2.687 & 2.720 & 2.760 & 2.793 \\
\hline & & 2 & 0 & 1.980 & 2.182 & 2.340 & 2.486 & 2.638 & 2.760 & 2.870 & 2.943 & 2.984 & 3.001 \\
\hline & & 3 & 0 & 2.031 & 2.324 & 2.455 & 2.557 & 2.632 & 2.732 & 2.784 & 2.815 & 2.861 & 2.922 \\
\hline & \multirow{3}{*}{ IAPS } & 4 & 0 & 1.507 & 1.810 & 1.967 & 2.085 & 2.178 & 2.244 & 2.287 & 2.321 & 2.348 & 2.396 \\
\hline & & 5 & 0 & 1.449 & 1.714 & 1.861 & 1.972 & 2.054 & 2.118 & 2.184 & 2.251 & 2.320 & 2.378 \\
\hline & & 6 & 0 & 1.607 & 1.880 & 2.041 & 2.143 & 2.249 & 2.320 & 2.380 & 2.432 & 2.470 & 2.512 \\
\hline \multirow{6}{*}{1.2} & \multirow{3}{*}{ TAPS } & 7 & 0 & 2.791 & 3.268 & 3.537 & 3.792 & 3.972 & 4.109 & 4.235 & 4.377 & 4.485 & 4.575 \\
\hline & & 8 & 0 & 2.863 & 3.363 & 3.674 & 3.903 & 4.070 & 4.244 & 4.359 & 4.460 & 4.601 & 4.717 \\
\hline & & 9 & 0 & 2.859 & 3.374 & 3.732 & 3.968 & 4.149 & 4.305 & 4.449 & 4.591 & 4.724 & 4.849 \\
\hline & \multirow{3}{*}{ IAPS } & 10 & 0 & 2.350 & 2.795 & 3.068 & 3.268 & 3.443 & 3.560 & 3.664 & 3.774 & 3.860 & 3.949 \\
\hline & & 11 & 0 & 2.485 & 2.988 & 3.270 & 3.476 & 3.641 & 3.792 & 3.914 & 4.015 & 4.114 & 4.203 \\
\hline & & 12 & 0 & 2.387 & 2.855 & 3.151 & 3.379 & 3.568 & 3.710 & 3.869 & 4.006 & 4.112 & 4.205 \\
\hline
\end{tabular}

TABLE 9: Differences between the rut depths of two pavement structures with the same number of load cycles (load pressure $=0.7 \mathrm{MPa})$.

\begin{tabular}{|c|c|c|c|c|c|c|}
\hline Load cycles (times) & Error sources & Sum of squares & D. f. & Mean square & $F$ & Significance \\
\hline \multirow{3}{*}{2550} & Between groups & 0.25 & 1 & 0.25 & & \\
\hline & Within groups & 0.05 & 4 & 0.01 & 19.68 & $7.71^{*}$ \\
\hline & Total & 0.30 & 5 & & & \\
\hline \multirow{3}{*}{5100} & Between groups & 0.24 & 1 & 0.24 & & \\
\hline & Within groups & 0.04 & 4 & 0.01 & 25.87 & $7.71^{*}$ \\
\hline & Total & 0.28 & 5 & & & \\
\hline \multirow{3}{*}{7650} & Between groups & 0.25 & 1 & 0.25 & & \\
\hline & Within groups & 0.03 & 4 & 0.01 & 32.33 & $7.71^{*}$ \\
\hline & Total & 0.28 & 5 & & & \\
\hline \multirow{3}{*}{10200} & Between groups & 0.28 & 1 & 0.28 & & \\
\hline & Within groups & 0.02 & 4 & 0.01 & 52.94 & $7.71^{*}$ \\
\hline & Total & 0.30 & 5 & & & \\
\hline \multirow{3}{*}{12750} & Between groups & 0.31 & 1 & 0.31 & & \\
\hline & Within groups & 0.02 & 4 & 0.01 & 55.76 & $7.71^{*}$ \\
\hline & Total & 0.33 & 5 & & & \\
\hline \multirow{3}{*}{15300} & Between groups & 0.35 & 1 & 0.35 & & \\
\hline & Within groups & 0.03 & 4 & 0.01 & 50.70 & $7.71^{*}$ \\
\hline & Total & 0.38 & 5 & & & \\
\hline \multirow{3}{*}{17850} & Between groups & 0.37 & 1 & 0.37 & & \\
\hline & Within groups & 0.04 & 4 & 0.01 & 41.13 & $7.71^{*}$ \\
\hline & Total & 0.41 & 5 & & & \\
\hline \multirow{3}{*}{20400} & Between groups & 0.36 & 1 & 0.36 & & \\
\hline & Within groups & 0.04 & 4 & 0.01 & 34.73 & $7.71^{*}$ \\
\hline & Total & 0.40 & 5 & & & \\
\hline \multirow{3}{*}{22950} & Between groups & 0.36 & 1 & 0.36 & & \\
\hline & Within groups & 0.04 & 4 & 0.01 & 37.86 & $7.71^{*}$ \\
\hline & Total & 0.40 & 5 & & & \\
\hline \multirow{3}{*}{25500} & Between groups & 0.34 & 1 & 0.34 & & \\
\hline & Within groups & 0.03 & 4 & 0.01 & 41.78 & $7.71^{*}$ \\
\hline & Total & 0.37 & 5 & & & \\
\hline
\end{tabular}

* significant at $P<0.05$.

As shown in Table 12, when the wheel load is increased from $0.7 \mathrm{MPa}$ to $1.2 \mathrm{MPa}$, the rut depths of the different pavement structures increase by $63 \%$ or $72 \%$ depending on the pavement layer structure.

\subsubsection{Effect of the Pavement Structure on Pavement Rutting.} Based on the values presented in Table 11, the effect of the type of pavement structure with the same wheel loads on the maximum rut depth is shown in Table 13 , where $\mathrm{RD}_{\text {IAPS }}$ and $\mathrm{RD}_{\mathrm{TAPS}}$ denote the maximum rut depths of the IAPS and TAPS, respectively. Furthermore, $\left(\mathrm{RD}_{\text {IAPS }} / \mathrm{RD}_{\mathrm{TAPS}}\right)$ denotes the ratio of the maximum rut depth of the IAPS to that of the TAPS under the same wheel load.

As shown in Table 13, the IAPS sample contained ruts that were $16 \%$ and $12 \%$ shallower than those in the TAPS sample under the same wheel loads of $0.7 \mathrm{MPa}$ and $1.2 \mathrm{MPa}$, respectively. 
TABLE 10: Differences between the rut depths of two pavement structures with the same number of load cycles $($ load pressure $=1.2 \mathrm{MPa})$.

\begin{tabular}{|c|c|c|c|c|c|c|}
\hline Load cycles (times) & Error sources & Sum of squares & D. $f$. & Mean square & $F$ & Significance \\
\hline \multirow{3}{*}{2550} & Between groups & 0.28 & 1 & 0.28 & & \\
\hline & Within groups & 0.01 & 4 & 0.00 & 85.42 & $7.71^{*}$ \\
\hline & Total & 0.29 & 5 & & & \\
\hline \multirow{3}{*}{5100} & Between groups & 0.31 & 1 & 0.31 & & \\
\hline & Within groups & 0.03 & 4 & 0.01 & 47.36 & $7.71^{*}$ \\
\hline & Total & 0.34 & 5 & & & \\
\hline \multirow{3}{*}{7650} & Between groups & 0.35 & 1 & 0.35 & & \\
\hline & Within groups & 0.04 & 4 & 0.01 & 34.65 & $7.71^{*}$ \\
\hline & Total & 0.39 & 5 & & & \\
\hline \multirow{3}{*}{10200} & Between groups & 0.40 & 1 & 0.40 & & \\
\hline & Within groups & 0.04 & 4 & 0.01 & 42.16 & $7.71^{*}$ \\
\hline & Total & 0.43 & 5 & & & \\
\hline \multirow{3}{*}{12750} & Between groups & 0.39 & 1 & 0.39 & & \\
\hline & Within groups & 0.04 & 4 & 0.01 & 44.13 & $7.71^{*}$ \\
\hline & Total & 0.43 & 5 & & & \\
\hline \multirow{3}{*}{15300} & Between groups & 0.42 & 1 & 0.42 & & \\
\hline & Within groups & 0.05 & 4 & 0.01 & 35.52 & $7.71^{*}$ \\
\hline & Total & 0.47 & 5 & & & \\
\hline \multirow{3}{*}{17850} & Between groups & 0.42 & 1 & 0.42 & & \\
\hline & Within groups & 0.06 & 4 & 0.01 & 28.97 & $7.71^{*}$ \\
\hline & Total & 0.48 & 5 & & & \\
\hline \multirow{3}{*}{20400} & Between groups & 0.44 & 1 & 0.44 & & \\
\hline & Within groups & 0.06 & 4 & 0.02 & 29.33 & $7.71^{*}$ \\
\hline & Total & 0.51 & 5 & & & \\
\hline \multirow{3}{*}{22950} & Between groups & 0.50 & 1 & 0.50 & & \\
\hline & Within groups & 0.07 & 4 & 0.02 & 27.81 & $7.71^{*}$ \\
\hline & Total & 0.57 & 5 & & & \\
\hline \multirow{3}{*}{25500} & Between groups & 0.53 & 1 & 0.53 & & \\
\hline & Within groups & 0.08 & 4 & 0.02 & 26.22 & $7.71^{*}$ \\
\hline & Total & 0.61 & 5 & & & \\
\hline
\end{tabular}

*significant at $P<0.05$.

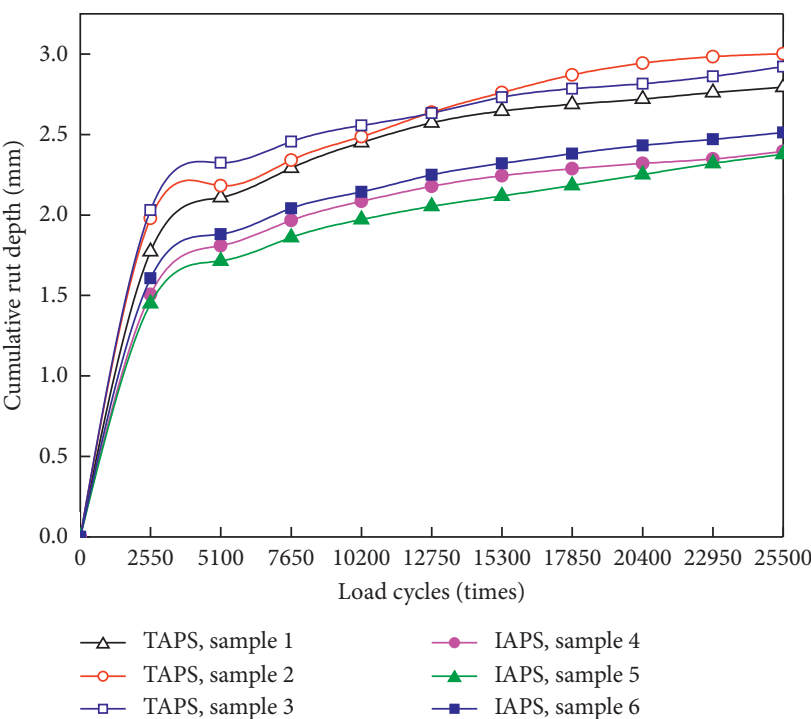

(a)

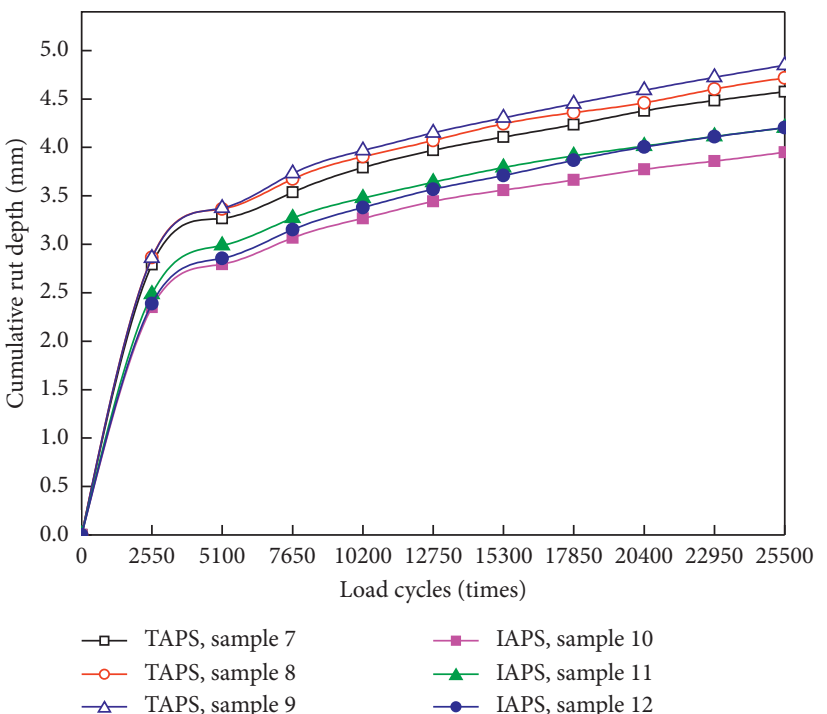

(b)

Figure 7: Cumulative rut depth trend with the number of loading cycles: (a) wheel load $=0.7 \mathrm{MPa}$ and (b) wheel load $=1.2 \mathrm{MPa}$. 
TABle 11: Coefficients of the rutting prediction equation.

\begin{tabular}{lcccccc}
\hline \multirow{2}{*}{ Load (MPa) } & \multicolumn{3}{c}{ TAPS } & \multicolumn{3}{c}{ IAPS } \\
& $\mathrm{RD}_{\max }$ & $\xi$ & $R^{2}$ & $\mathrm{RD}_{\max }$ & $\xi$ & $R^{2}$ \\
\hline 0.7 & 3.025 & 1730 & 0.993 & 2.537 & 1965 & 0.995 \\
1.2 & 4.924 & 2271 & 0.990 & 4.355 & 2482 & 0.991 \\
\hline
\end{tabular}

TABLE 12: Maximum rut depth ratio under different load pressures.

\begin{tabular}{lcc}
\hline Pavement structures & TAPS & IAPS \\
\hline$\left(\mathrm{RD}_{1.2} / \mathrm{RD}_{0.7}\right)$ & 1.63 & 1.72 \\
\hline
\end{tabular}

TABLE 13: Maximum rut depth ratio of the two pavement structures under the same wheel load.

\begin{tabular}{lccc}
\hline Load $(\mathrm{MPa})$ & $\mathrm{RD}_{\mathrm{TAPS}}$ & $\mathrm{RD}_{\mathrm{IAPS}}$ & $\left(\mathrm{RD}_{\mathrm{IAPS}} / \mathrm{RD}_{\mathrm{TAPS}}\right)$ \\
\hline 0.7 & 3.025 & 2.537 & 0.839 \\
1.2 & 4.924 & 4.355 & 0.884 \\
\hline
\end{tabular}

\section{Conclusions}

An inverted asphalt pavement structure was proposed in this study, and the rutting resistance of the inverted asphalt pavement structure was evaluated. The following conclusions can be obtained from the abovementioned results.

(1) When compared with the TAPS, the maximum shear stress of the IAPS can be reduced by approximately $1.7 \%$. These results show that the IAPS can reduce the maximum shear stress of asphalt pavements.

(2) Two rutting prediction equations of asphalt pavement structures were established, and the correlation coefficients $R^{2}$ exceeded 0.98 . This high $R^{2}$ value indicates that the proposed rutting prediction equation can accurately predict the rut development in asphalt pavements.

(3) When compared with the TAPS, the rutting resistance of the IAPS under the wheel load of $0.7 \mathrm{MPa}$ and $1.2 \mathrm{MPa}$ can be increased by $16 \%$ and $12 \%$, respectively. Furthermore, the increase in wheel load affects the rutting performances of both pavement structures in a similar manner. When the wheel load is increased from $0.7 \mathrm{MPa}$ to $1.2 \mathrm{MPa}$, the rut depths of the different pavement structures increase by $63 \%$ or $72 \%$ depending on the pavement layer structure.

The aforementioned tests compared the rutting resistance of the TAPS and IAPS with different numbers of load cycles $(\leq 25500)$. The effect of more load cycles will be observed in our future studies to further verify the reliability of the proposed rutting prediction equations and the superiority of the IAPS. Moreover, the paper primarily focused on the rutting resistance of the IAPS; the fatigue property of the IAPS also will be studied in our further work.

\section{Data Availability}

The data used to support the findings of this study are included within the article.

\section{Conflicts of Interest}

The authors declare that there are no conflicts of interest regarding the publication of this paper.

\section{Acknowledgments}

The research was supported by the Science and Technology Project of Zhejiang Provincial Department of Transportation (No. 2016020), the Science and Technology Project of Henan Provincial Department of Transportation (No. 2020J-2-2), and the Scientific Research of Central Colleges of China for Chang'an University (No. 300102218212). The authors gratefully acknowledge these financial supports.

\section{References}

[1] V. D. Jarnette, L. M. McCarthy, T. Bennert, and M. C. Guercio, "Use of mechanistic-empirical pavement design principles to assign asphalt pavement pay factor adjustments," Journal of Construction Engineering and Management, vol. 139, no. 11, Article ID 04013024, 2013.

[2] M. Zheng, L. Han, F. Wang, H. Mi, Y. Li, and L. He, "Comparison and analysis on heat reflective coating for asphalt pavement based on cooling effect and anti-skid performance," Construction and Building Materials, vol. 93, pp. 1197-1205, 2015.

[3] W. S. Mogawer, A. J. Austerman, J. S. Daniel, F. J. Zhou, and T. Bennert, "Evaluation of the effects of hot mix asphalt density on mixture fatigue performance, rutting performance and MEPDG distress predictions," International Journal of Pavement Engineering, vol. 12, no. 2, pp. 161-175, 2011.

[4] R. Gogoi, A. Das, and P. Chakroborty, "Are fatigue and rutting distress modes related?" International Journal of Pavement Research and Technology, vol. 6, no. 4, pp. 269-273, 2013.

[5] Y. F. Du, J. Q. Chen, Z. Han, and W. Z. Liu, "A review on solutions for improving rutting resistance of asphalt pavement and test methods," Construction and Building Materials, vol. 168, pp. 893-905, 2018.

[6] A. I. Al-Hadidy and Y. Q. Tan, "Effect of styrene-butadienestyrene on the properties of asphalt and stone-matrix-asphalt mixture," Journal of Materials in Civil Engineering, vol. 23, no. 4, pp. 504-510, 2011.

[7] V. O. Bulatovic, V. Rek, and K. J. Marković, "Rheological properties and stability of ethylene vinyl acetate polymermodified bitumen," Polymer Engineering and Science, vol. 53, no. 11, pp. 2276-2283, 2013.

[8] H. Y. Yin, Y. G. Zhang, Y. F. Sun et al., "Performance of hot mix epoxy asphalt binder and its concrete," Materials and Structures, vol. 48, no. 11, pp. 3825-3835, 2015.

[9] G. L. Zou and C. Wu, "Evaluation of rheological properties and field applications of buton rock asphalt," Journal of Testing and Evaluation, vol. 43, no. 5, pp. 1146-1156, 2015.

[10] C. Q. Fang, X. Yu, R. E. Yu, P. Liu, and X. T. Qiao, "Preparation and properties of isocyanate and nano particles composite modified asphalt," Construction and Building Materials, vol. 119, pp. 113-118, 2016.

[11] H. Geng, C. S. Clopotel, and H. U. Bahia, "Effects of high modulus asphalt binders on performance of typical asphalt pavement structures," Construction and Building Materials, vol. 44, pp. 207-213, 2013. 
[12] P. Hajikarimi, M. Rahi, and F. M. Nejad, "Comparing different rutting specification parameters using high temperature characteristics of rubber-modified asphalt binders," Road Materials and Pavement Design, vol. 16, no. 4, pp. 751-766, 2015.

[13] Z. J. Dong, G. Q. Xiao, and X. B. Gong, "Analysis on impact of gradation and anti-rutting additive on rutting resistance of asphalt mixture," Journal of Highway and Transportation Research and Development, vol. 31, no. 2, pp. 27-31, 2014.

[14] S. Kim, G. A. Sholar, T. Byron, and J. Kim, "Performance of polymer-modified asphalt mixture with reclaimed asphalt pavement," Transportation Research Record, vol. 2126, no. 2126, pp. 109-114, 2009.

[15] A. Bernier, A. Zofka, and I. Yut, "Laboratory evaluation of rutting susceptibility of polymer-modified asphalt mixtures containing recycled pavements," Construction and Building Materials, vol. 31, pp. 58-66, 2012.

[16] M. Nazirizad, A. Kavussi, and A. Abdi, "Evaluation of the effects of anti-stripping agents on the performance of asphalt mixtures," Construction and Building Materials, vol. 84, pp. 348-353, 2015.

[17] A. K. Das and D. Singh, "Investigation of rutting, fracture and thermal cracking behavior of asphalt mastic containing basalt and hydrated lime fillers," Construction and Building Materials, vol. 141, pp. 442-452, 2017.

[18] Z. G. Wang, Q. L. Dai, and S. C. Guo, "Laboratory performance evaluation of both flake graphite and exfoliated graphite nanoplatelet modified asphalt composites," Construction and Building Materials, vol. 149, pp. 515-524, 2017.

[19] S. P. Wu, Y. J. Xue, Q. S. Ye, and Y. C. Chen, "Utilization of steel slag as aggregates for stone mastic asphalt (SMA) mixtures," Building and Environment, vol. 42, no. 7, pp. 2580-2585, 2007.

[20] E. A. Oluwasola, M. R. Hainin, and M. M. A. Aziz, "Comparative evaluation of dense-graded and gap-graded asphalt mix incorporating electric arc furnace steel slag and copper mine tailings," Journal of Cleaner Production, vol. 122, pp. 315-325, 2016.

[21] E. Coleri, J. T. Harvey, K. Yang, and J. M. Boone, "Investigation of asphalt concrete rutting mechanisms by X-ray computed tomography imaging and micromechanical finite element modeling," Materials and Structures, vol. 46, no. 6, pp. 1027-1043, 2013.

[22] H. K. Shanbara, F. Ruddock, and W. Atherton, "A viscoplastic model for permanent deformation prediction of reinforced cold mix asphalt," Construction and Building Materials, vol. 186, pp. 287-302, 2018.

[23] H. K. Shanbara, A. Shubbar, F. Ruddock, and W. Atherton, "Characterizing the rutting behaviour of reinforced cold mix asphalt with natural and synthetic fibres using finite element analysis," in Advances in Structural Engineering and Rehabilitation, pp. 221-227, Springer Nature, Singapore, 2020.

[24] M. Santamouris, "Using cool pavements as a mitigation strategy to fight urban heat island-a review of the actual developments," Renewable and Sustainable Energy Reviews, vol. 26, no. 10, pp. 224-240, 2013.

[25] Y. J. Jiang, C. Q. Deng, Z. J. Chen, and Y. H. Tian, "Evaluation of the cooling effect and anti-rutting performance of thermally resistant and heat-reflective pavement," International Journal of Pavement Engineering, vol. 21, no. 4, pp. 447-456, 2020.

[26] Y. J. Jiang, Y. Q. Ye, J. S. Xue, and Z. J. Chen, “Thermal resistant stone mastic asphalt surface and its anti-rutting performance," Journal of Materials in Civil Engineering, vol. 30, no. 11, Article ID 06018019, 2018.

[27] T. Ma, Y. Zhong, T. Tang, and X. M. Huang, "Design and evaluation of heat-resistant asphalt mixture for permafrost regions," International Journal of Civil Engineering, vol. 14, no. 5, pp. 339-346, 2016.

[28] T. Xu and X. M. Huang, "Investigation into causes of in-place rutting in asphalt pavement," Construction and Building Materials, vol. 28, no. 1, pp. 525-530, 2012.

[29] H. Wang, Q. S. Zhang, and J. Q. Tan, "Investigation of layer contributions to asphalt pavement rutting," Journal of $\mathrm{Ma}$ terials in Civil Engineering, vol. 21, no. 4, pp. 181-185, 2009.

[30] J. Yang, L. M. Yu, J. Wang, J. Chen, and G. C. Qian, "Rutting resistance of asphalt mixtures in the middle course," Journal of Southeast University (English Edition), vol. 22, no. 2, pp. 270-272, 2006.

[31] Z. Z. Li, S. F. Chen, W. D. Liao, and H. X. Chen, "Evaluation of anti-cracking performance of modified HMA in stress absorbing layers under low temperature," China Journal of Highway and Transport, vol. 25, no. 4, pp. 29-35, 2012, in Chinese.

[32] Q. Li, H. H. Yang, F. J. Ni, X. Ma, and L. H. Luo, "Cause analysis on permanent deformation for asphalt pavements using field cores," Construction and Building Materials, vol. 100, pp. 40-51, 2015.

[33] Y. Zhang, X. Luo, Y. Deng, S. G. Hou, X. J. Shi, and R. L. Lytton, "Evaluation of rutting potential of flexible pavement structures using energy-based pseudo variables," Construction and Building Materials, vol. 247, Article ID 118391, 2020.

[34] D. Han, L. Wei, and J. Zhang, "Experimental study on performance of asphalt mixture designed by different method," Procedia Engineering, vol. 137, pp. 407-414, 2016.

[35] Ministry of Transport of the People's Republic of China, Standard Test Methods of Bitumen and Bituminous Mixtures for Highway Engineering (JTG E20-2011), China Communications Press, Beijing, China, 2011, in Chinese.

[36] Ministry of Transport of the People's Republic of China, Technical Specifications for Construction of Highway Asphalt Pavements (JTG F40-2004), China Communications Press, Beijing, China, 2004, in Chinese.

[37] Y. J. Jiang, C. Q. Deng, J. S. Xue, and Z. J. Chen, "Investigation into the performance of asphalt mixture designed using different methods," Construction and Building Materials, vol. 177, pp. 378-387, 2018.

[38] Y. J. Jiang, C. Q. Deng, Q. Li, and H. P. Liu, "Effect of compaction methods on physical and mechanical properties of asphalt mixture," Journal of Materials in Civil Engineering, vol. 31, no. 6, Article ID 04019075, 2019.

[39] Y. J. Jiang, C. Q. Deng, J. S. Xue, H. P. Liu, and Z. J. Chen, "Investigation of the fatigue properties of asphalt mixture designed using vertical vibration method," Road Materials and Pavement Design, vol. 21, no. 5, pp. 1454-1469, 2020.

[40] S. G. Hou, X. J. Shi, Y. Deng, and F. Gu, "Evaluation of rutting and friction resistance of hot mix asphalt concrete using an innovative vertically loaded wheel tester," Construction and Building Materials, vol. 176, pp. 710-719, 2018. 